\title{
O NOVELO DE TESEU DA LEGISLAÇÃO AMBIENTAL (OU: O MANUAL BÁSICO DE SOBREVIVÊNCIA PARA INICIANTES NO LABIRINTO DE DÉDALO)
}

\author{
THE NOVEL OF THESEUS OF THE ENVIRONMENTAL LEGISLATION \\ (OR: THE BASIC SURVIVAL GUIDE FOR BEGINNERS \\ IN THE DAEDALU'S LABYRINTH) \\ EL TESEO NOVELO DE LA LEY DEL MEDIO AMBIENTE \\ (O: LA GUÍA BÁSICA DE SUPERVIVENCIA PARA \\ PRINCIPIANTES EN EL LABERINTO DE DÉDALO)
}

\section{Marcelo Martins de Moura-Fé}

Geógrafo. Doutor em Geografia (PPGG-UFC). Professor do Departamento de Geociências da Universidade Regional do Cariri (DEGEO/URCA). Rua Cel. Antônio Luis, 116, CEP: 63.100-000, Pimenta, Crato/CE. Tels. (88)3102.1212 / 3102.1204.E-mail:marcelo.mourafe@urca.br

\section{Mônica Virna de Aguiar Pinheiro}

Geógrafa. Doutora em Ciências Marinhas Tropicais (Labomar-UFC). Professora do DEGEO/URCA. Rua Cel. Antônio Luis, 116, CEP: 63.100-000, Pimenta, Crato/CE. Tels. (88) 3102.1212 / 3102.1204. E-mail:monivirna@yahoo.com.br

\section{Anatarino Torres da Costa}

Geógrafa. Mestre em Geografia (PPGG-UFC). Analista em gestão de recursos hídricos pela Companhia de Gestão dos Recursos Hídricos do Estado do Ceará - COGERH. Rua José Amaro, 208, CEP: 63.501.002, Bugi, Iguatu/CE. Tel. (88) 3581.0800.E-mail:anatarino@yahoo.com.br

\section{RESUMO}

Apoiados em nossa experiência profissional e acadêmica, nos colocamos como a princesa Ariadne no papel de auxiliar as novas e os novos "Teseus" a desbravarem as leis, decretos-leis, resoluções, temas, objetivos e princípios presentes na legislação ambiental brasileira, algo fundamental para quem trabalha com as questões ambientais, realizando a interface entre sociedade e natureza com a finalidade de buscar alguma aplicabilidade, seja no campo do planejamento seja no âmbito da gestão.

Acreditamos que com esse novelo em forma de artigo você possa fazer uma imersão destemida pelo labirinto da legislação ambiental, seguro em fazer novas descobertas e em encontrar o caminho de volta, sem medo de ter o minotauro à espreita, confiante de que é esse o processo para realizar sua contribuição para as melhorias das condições do nosso meio ambiente através da legislação ambiental.

Palavras-chave: Planejamento Ambiental; Gestão Territorial; Desenvolvimento Sustentável; Áreas de Preservação Permanente; Unidades de Conservação. 


\section{ABSTRACT}

Based on our professional and academic experience, we have become like Princess Ariadne in the role of helping new and new "Teseus" to unfold laws, decrees, laws, themes, objectives and principles present in Brazilian environmental legislation. For those who work with environmental issues, making the interface between society and nature with the purpose of seeking some applicability, be it in the field of planning or in the scope of management. We believe that with this ball in article form you can do a fearless immersion through the maze of environmental legislation, sure to make new discoveries and find the way back without fear of having the minotaur lurking, confident that this is the process To make its contribution to the improvement of the conditions of our environment through environmental legislation.

Key words: Environmental planning; Territorial Management; Sustainable development; Areas of Permanent Preservation; Conservation units.

\section{RESUMEN}

Con el respaldo de nuestra experiencia profesional y académica, nos ponemos como princesa Ariadna en el papel de asistencia a los nuevos y los nuevos "Theseus" las leyes desbravarem, decretos-leyes, resoluciones, temas, objetivos y principios presentes en la legislación ambiental brasileña, algo fundamental para los que trabajan con temas ambientales, por lo que la interfaz entre la sociedad y la naturaleza con el fin de buscar alguna aplicación, ya sea en el campo de la planificación es en la gestión. Creemos que con este artículo en forma de bola que puede hacer una zambullida sin miedo a través del laberinto de la legislación ambiental, salvo en hacer nuevos descubrimientos y encontrar el camino de vuelta, sin temor a que el minotauro se ocultaba seguro de que este es el proceso para hacer su contribución a la mejora de las condiciones de nuestro entorno a través de la legislación ambiental.

Palabras clave: Planificación del medio ambiente; Manejo de la Tierra; Desenvolvimiento sustentable; Áreas de Preservación Permanente; Unidades de conservación. 


\section{INTRODUÇÃO}

Teseu era filho de Egeu (rei de Atenas) e de Etra (filha do rei de Trézen, por quem foi criado). Adulto, foi mandado para Atenas e entregue ao seu pai. Inspirado em Hércules, cuja fama corria, Teseu sentia em si o espírito e a alma de herói e realizou, desde muito jovem, viagens perigosas e protagonizou aventuras icônicas na mitologia grega, dentre elas, as lutas contra Epidauro, Protusco e Medéia.

Logo ao chegar em Atenas, Teseu presenciou a grande aflição que o povo sofria devido ao tributo que eram obrigados a pagar a Minos, rei de Tebas. Esse tributo consistia em sete jovens e sete donzelas que eram entregues todos os anos para serem devorados pelo Minotauro, lendário monstro com corpo de homem e cabeça de touro, forte, implacável e feroz, que era mantido numa labirinto construído por Dédalo, e tão habilmente projetado que quem entrasse não conseguiria sair, pelo menos, não sem ajuda.

Destemido, Teseu resolveu acabar com aquilo, ou morrer tentando. Assim, quando chegou a ocasião de enviar o tributo e os jovens serem sorteados (forma utilizada para escolha), ele se ofereceu para ser uma das vítimas, para desespero do pai. O navio partiu para Creta e, chegando lá, todos foram exibidos para o rei Minos e Ariadne, filha do rei, que estava presente e que apaixonou-se imediatamente por Teseu, tendo este amor prontamente correspondido.

Ariadne deu-lhe, então, uma espada para enfrentar o Minotauro, e um novelo de linha, com o qual poderia usar para encontrar o caminho de saída do labirinto. Com essa ajuda Teseu tanto venceu o monstro quanto também conseguiu sair do labirinto, graças ao novelo dado por Ariadne, o novelo de Teseu, como ficou conhecido.

Este breve relato, construído a partir de Bulfinch (2006) e que permeia o imaginário de inúmeras pessoas, onde um jovem herói enfrenta um terrível monstro em um labirinto tido como invencível, nos inspirou para escrever esse artigo sobre o verdadeiro desafio que é imergir no campo da legislação ambiental brasileira, um verdadeiro labirinto de Dédalo para os iniciantes.

Apoiados em nossa experiência profissional e acadêmica, nos colocamos como a princesa Ariadne no papel de auxiliar as novas e os novos "Teseus" a desbravarem as leis, decretos-leis, resoluções, temas, objetivos e princípios presentes em cada canto da legislação ambiental brasileira, algo fundamental para todos aqueles que trabalham com as questões ambientais, realizando a interface entre sociedade e natureza com a finalidade de buscar alguma aplicabilidade, seja no campo do planejamento seja no âmbito da gestão. 
Obviamente, não pretendemos dar um manual completo de uso e/ou consulta, algo deveras pretencioso para um artigo, mas sim, nosso objetivo aqui é o de tecer um pequeno novelo de Teseu que possa inspirar e nortear nossos leitores, dando-lhes os elementos básicos e apontando possíveis caminhos para que todos possam entrar e sair do labirinto da legislação ambiental sem ter que, necessariamente, enfrentar um minotauro.

\section{MATERIAIS E MÉTODOS}

Para realizar a análise sobre a legislação ambiental brasileira e sua importância para o planejamento ambiental e a gestão do território foram adotadas conceituações teóricas históricas e contemporâneas, notadamente presentes na esfera federal e com interface nas esferas estadual e municipal. Associados a esses princípios teórico-norteadores foram adotadas técnicas de pesquisa que possibilitaram o desenvolvimento do objetivo, basicamente relacionadas a levantamentos bibliográficos criteriosos acerca das temáticas abordadas.

Esse arcabouço teórico, junto da experiência profissional dos autores enquanto consultores ambientais, técnicos no setor público, quanto acadêmicos (pesquisadores e professores), com a elaboração de diversos estudos ambientais para fins de licenciamento ambiental, recuperação de áreas degradadas, participação em mesas-redondas, audiências públicas, realização de palestras, mini-cursos, e na produção de artigos, nos permitiu construir a discussão que será apresentada adiante.

As informações levantadas e selecionadas foram discutidas e analisadas de forma segmentada e, posteriormente, integralizada, visando estabelecer aspectos inter-relacionados presentes desde a literatura científica específica até os títulos legais, o que permitiu tecer uma análise crítica sobre um possível caminho a ser seguido no desenvolvimento e aprofundamento sobre a temática da legislação ambiental.

\section{RESULTADOS E DISCUSSÕES}

\section{Batendo na porta do labirinto: O Desenvolvimento Sustentável}

Antes de se debruçar sobre a legislação, per si, é importante ter o entendimento de que os princípios fundamentais da legislação ambiental brasileira vigente passam pelo conceito de desenvolvimento sustentável, paradigma de desenvolvimento surgido nas décadas de 1970 e 1980 sobre os limites ao crescimento da população humana, da economia e da utilização dos recursos naturais. 
Os princípios do desenvolvimento sustentável estão presentes na Declaração do Rio, da Conferência das Nações Unidas para o Meio Ambiente e o Desenvolvimento (ECO-92), e também fundamentam a Agenda 21, onde se parte de um cenário atual para planejar o futuro de forma sustentável, com a participação da sociedade, numa abordagem integrada e sistêmica das dimensões econômica, social, ambiental e político-institucional da localidade (BRASIL, 2009).

Na sua essência, conforme Brasil (2002), o desenvolvimento sustentável procura integrar e harmonizar as ideias e conceitos relacionados ao crescimento econômico, a justiça e ao bem estar social, a conservação ambiental e a utilização racional dos recursos naturais. Para tanto considera as dimensões social, ambiental, econômica e institucional do desenvolvimento.

Em termos sociais propõe a repartição mais justa das riquezas produzidas (princípio da justiça social), a universalização do acesso à educação e à saúde, e a equidade entre sexos, grupos étnicos, sociais e religiosos, entre outros aspectos. Para ser sustentável, em suma, o desenvolvimento tem de significar melhoria na qualidade de vida de toda a população, assegurando condições de vida dignas a todos.

Do ponto de vista ambiental, propõe a utilização regrada dos recursos naturais, de forma a garantir o seu uso pelas gerações futuras; propõe que os recursos naturais renováveis sejam usados aquém de sua capacidade de renovação, e os recursos não renováveis de forma equilibrada. Propõe ainda a preservação de amostras significativas do ambiente natural, de forma a garantir a manutenção dos serviços ambientais que determinadas áreas propiciam e a qualidade de vida da população do entorno.

Quanto à economia, postula o crescimento baseado no aumento da eficiência de uso da energia e dos recursos naturais, além de mudanças nos padrões de consumo da sociedade e nos padrões de produção, com a redução do desperdício e maior consciência dos impactos causados pelo uso dos recursos naturais. Por fim, em termos institucionais, o desenvolvimento sustentável avalia o grau de participação e controle da sociedade sobre as instituições públicas e privadas, o aparelhamento do estado para lidar com as questões ambientais, o envolvimento em acordos internacionais, o montante de investimento em proteção ao meio ambiente, ciência e tecnologia e o acesso a novas tecnologias.

Munidos dos princípios contidos nessas dimensões do desenvolvimento sustentável e buscando acompanhar as demandas sociais ao longo das últimas décadas, legisladores brasileiros desenvolveram um cabedal de títulos legais que tiveram no Estado um protagonista irrefutável nesse contexto. 
Como se sabe, o surgimento do Estado se deu com o objetivo de intermediar e solucionar conflitos na sociedade na perspectiva da coletividade, ao passo que a relação entre Estado e sociedade está em um contrato social e em todas as instituições políticas legitimadas pelo governo, onde o cidadão é obrigado a cumprir leis, formando o pacto-constituinte (SIRVINSKAS, 2015).

O conceito de Estado moderno, em parte, tem suas bases no livro "Leviatã" (HOBBES, 1651), onde o homem, enquanto ser social egoísta e com tendências ao conflito, precisa de um leviatã (monstro bíblico) que puna aqueles que não obedecem ao contrato social. A partir desse preâmbulo sucinto, a pergunta: como o Estado regula a sociedade?, pode ser respondida em poucas palavras da seguinte forma: o Estado regula a sociedade através de leis. Assim, para aplicar os princípios do desenvolvimento sustentável na sociedade, repleta de interesses contraditórios, o Estado atuou da forma como costuma historicamente atuar: através das leis.

Dito isso, agora podemos entrar no labirinto, não sem antes amarrar fortemente a ponta do novelo no conceito do desenvolvimento sustentável, o que permitirá, sempre que quisermos, voltar ao princípio da caminhada e entender onde ela começa.

\section{Desfiando o novelo: desvendando os Códigos Florestais}

$\mathrm{Na}$ tentativa de ordenar os diversos interesses envolvidos na utilização das terras, o Estado brasileiro vem regulamentando o uso e ocupação do solo por meio de promulgação de leis, decretos e resoluções, desde a década de 1930 (MARCHIORO et al., 2010).

No ano de 1934, vivia-se uma forte expansão cafeeira no país e, partir disso surgiu o $1^{\circ}$ Código Florestal. Principalmente no Sudeste, empurradas e suprimidas pelas frentes de plantações, as florestas ficavam cada vez mais distantes das principais cidades, dificultando e encarecendo o transporte de lenha. Desta forma, a legislação visava, sobretudo, impedir os efeitos sociais e políticos negativos causados pelo aumento do preço, ou pior, pela falta da lenha, garantindo, dessa forma, a popularidade do novo regime, instaurado com a Revolução de 1930 (BRASIL, 2012a).

Com esse pano de fundo, esse primeiro Código Florestal apresentou avanços na preservação ambiental, ao criar a figura das florestas protetoras para garantir a qualidade ambiental de rios e lagos e a estabilidade de áreas de risco (encostas íngremes e dunas, por exemplo). Mais tarde, esse conceito deu origem às áreas de preservação permanente (APPs) (PINHEIRO et al., 2013a). 
Décadas depois, com o advento dos novos combustíveis e fontes de energia no território brasileiro, como as hidrelétricas, a lenha foi deixando paulatina e progressivamente de ter importância econômica. De maneira inversa, crescia a consciência do papel do meio ambiente e das florestas. Assim, em 1960, o Legislativo se mobilizou para alterar a lei de 1934 (BRASIL, 2012b).

Assim, em 15 de setembro de 1965, Castelo Branco sancionava a Lei Federal no 4.771, o "novo Código Florestal”, que estabelecia a figura da Reserva Legal (50\% na Amazônia e $20 \%$ no restante do país - art. 16) e definia a localização das Áreas de Preservação Permanente - APPs (art. 2 e 3). Além disso, essa lei também definiu as áreas de preservação permanente (APPs) que deveriam ser obrigatoriamente mantidas, no campo ou nas cidades (PINHEIRO et al., 2013a).

Apesar de ser uma lei importante para a sociedade, houve uma imensa pressão para alterá-la e mesmo para revoga-la, por exemplo, de parte do setor agropecuário brasileiro, interessado na expansão de suas atividades que, comumente, encontrava nas florestas e no seu código de proteção verdadeiros obstáculos.

O anseio por um novo código florestal foi alimentado por décadas até o ano de 2012. Até o momento da sua promulgação, cerca de 36 projetos de lei tentaram derrubar o Código Florestal vigente, advindos, sobretudo, do setor relacionado ao agronegócio brasileiro. Apesar disso, em maio de 2012 foi sancionada a Lei federal no 12.651/2012 que "dispõe sobre a proteção da vegetação nativa". Em seu Art. $\mathbf{1}^{\mathbf{0}}$-A, esta Lei estabelece normas gerais sobre a proteção da vegetação, APPs e as áreas de Reserva Legal; a exploração florestal, o suprimento de matéria-prima florestal, o controle da origem dos produtos florestais e o controle e prevenção dos incêndios florestais, e prevê instrumentos econômicos e financeiros para o alcance de seus objetivos (BRASIL, 2012c).

Apesar de alguns retrocessos do ponto de vista da proteção ambiental, por exemplo, ao não considerar o caráter ecossistêmico das feições geomorfológicas da paisagem, fomentando a proteção setorizada ao não incluir feições importantes como APPs, o que implica em lacunas de proteção em ecossistemas de maior escala de amplitude (MOURA-FÉ et al., 2014; 2015; PINHEIRO et al., 2013b), e a não consideração das APPs dos rios a partir do seu leito maior, o atual Código Florestal teve mérito ao consolidar a figura legal das APPs.

Já presentes no Codigo Florestal de 1965, as APPs são definidas em margens de cursos d'água, lagos, lagoas e reservatórios artificiais, topos de morros e encostas com declividade elevada, cobertas ou não por vegetação nativa, com a função ambiental de preservar os recursos hídricos, a paisagem, a estabilidade geológica, a biodiversidade, o fluxo gênico 
de fauna e flora, e de proteger o solo e assegurar o bem estar da população humana. São consideradas áreas mais sensíveis e sofrem riscos de erosão do solo, enchentes e deslizamentos (BRASIL, 1965; 2012c).

Assim, é fundamental entender o que são, a importância e, para aqueles que trabalham com estudos ambientais com fins de licenciamento ambiental, sobretudo, buscar identificar as APPs. Para todos os casos, no contexto da Lei no 12.651/2012 é obrigatório conhecer o art. $4^{\circ}$ e seus diversos parágrafos.

O primeiro parágrafo delimita as faixas marginais de qualquer curso d'água natural perene e intermitente, excluídos os efêmeros, desde a borda da calha do leito regular, em largura mínima que deriva de 30 até 500 metros, em função da largura do leito dos cursos d'água correlatos (Figura 1). Já o $2^{\circ}$ parágrafo se atém para as áreas no entorno dos lagos e lagoas naturais, que têm sua faixa de proteção variando em função da localização em zonas rurais ou urbanas, o que é legalmente definido nos planos diretores dos municípios, documento imprescindível nesses casos para que se tenha segurança legal.

Figura 1: APP de margens de cursos d'agua. In: Cartilha do Código Florestal Brasileiro. Fonte: http:// www.ciflorestas.com.br/cartilha/. Acesso em: 15/Nov/2016.

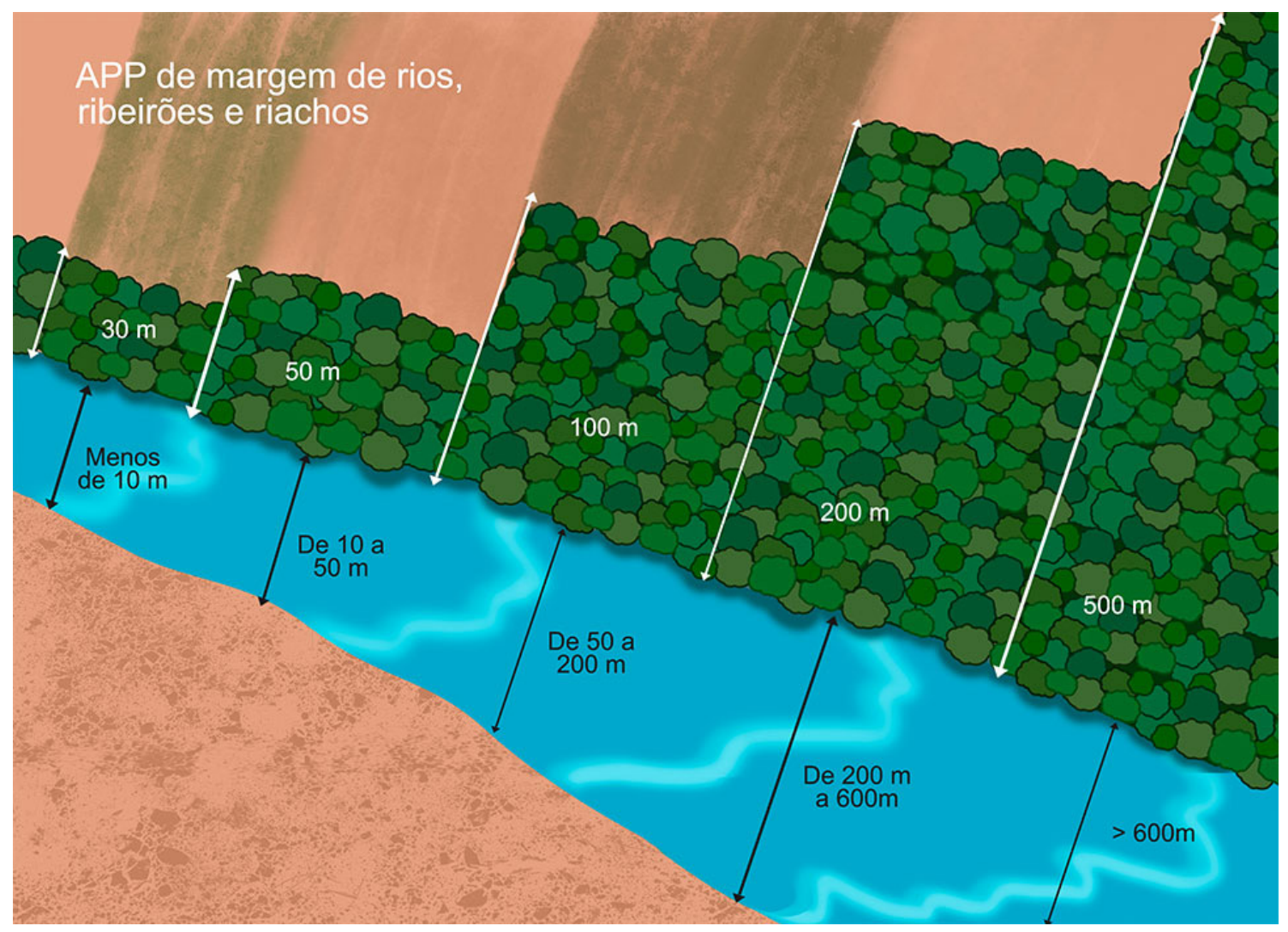


Por sua vez, o parágrafo III traz um retrocesso, ao passo que diz que as áreas no entorno dos reservatórios d'água artificiais, decorrentes de barramento ou represamento de cursos d'água naturais, terão faixas de proteção definidas na licença ambiental do empreendimento, ao passo que anteriormente (1965) essa faixa já era definida, não deixando essa definição para as mãos de um processo sujeito à inúmeras pressões e embates, onde o interesse ambiental nem sempre prevalece, face a interesses econômicos/particulares diversos..

Ainda no art. $4^{\circ}$ do Código Florestal vigente no Brasil, o parágrafo IV trata das áreas no entorno das nascentes e dos olhos d'água perenes, em qualquer que seja sua situação topográfica, com raio mínimo de 50 metros (Figura 2); e o parágrafo V aborda as encostas ou partes destas com declividade superior a $45^{\circ}$, que é equivalente a $100 \%$ (cem por cento) na linha de maior declive e, por fim, o parágrafo VI, as restingas, como fixadoras de dunas ou estabilizadoras de mangues.

Importante, como já pode ser percebido, o art. $4^{\circ}$ é extenso e ainda traz a delimitação sobre os manguezais (parágrafo VII), sobre as bordas dos tabuleiros ou chapadas, até a linha de ruptura do relevo, em faixa nunca inferior a 100 (cem) metros em projeções horizontais (parágrafo VIII - Figura 3); traz no parágrafo IX a delimitação dos topos de morros, montes, montanhas e serras; as áreas em altitude superior a 1.800 (mil e oitocentos) metros, qualquer que seja a vegetação (parágrafo X); e as veredas (parágrafo XI). É um artigo fundamental e precisa ser compreendido.

Principal herança dos Códigos Florestais, sob o ponto de vista da proteção quase irrestrita das feições naturais e fatores correlatos (vegetação, clima, solos), as APPs apresentam-se como um ente legal de caráter eminentemente prático, aplicável. Mas, como acontece em inúmeros casos dentro da legislação ambiental, a sua aplicabilidade é precedida pela teoria e, estas questões teóricas, herdadas do conceito de desenvolvimento sustentável, conforme visto anteriormente, não "caíram de paraquedas" no nosso labirinto, elas têm endereço em um diploma legal que é fundamental para se entender a legislação ambiental brasileira. Será o nosso próximo passo. 
Figura 2: APP no entorno de nascentes e olhos d'água perenes. In: Cartilha do Código Florestal Brasileiro.

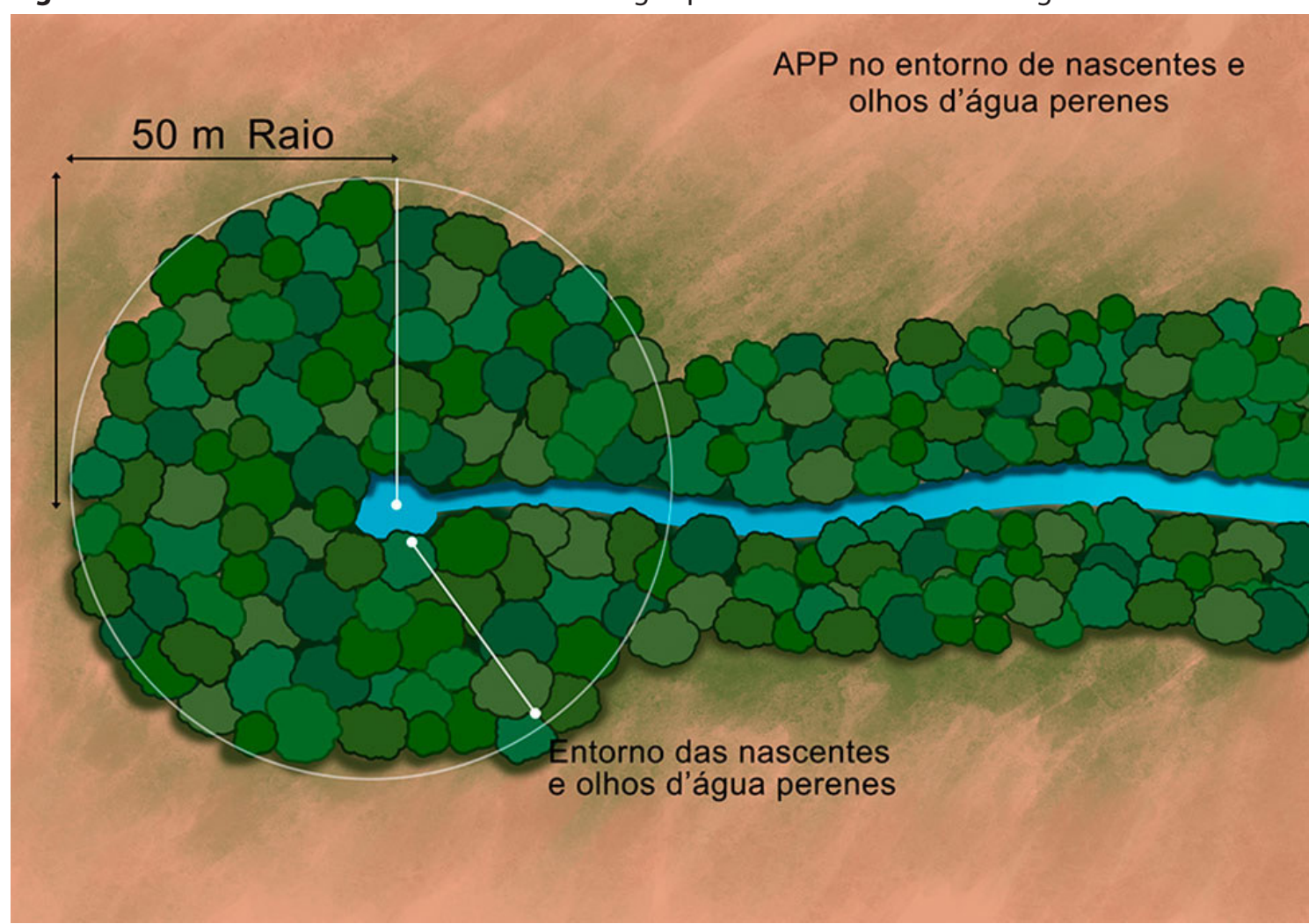

Fonte: http://www.ciflorestas.com.br/cartilha/. Acesso em: 15/Nov/2016.

Figura 3: APP em borda de tabuleiros e de chapadas. In: Cartilha do Código Florestal Brasileiro.

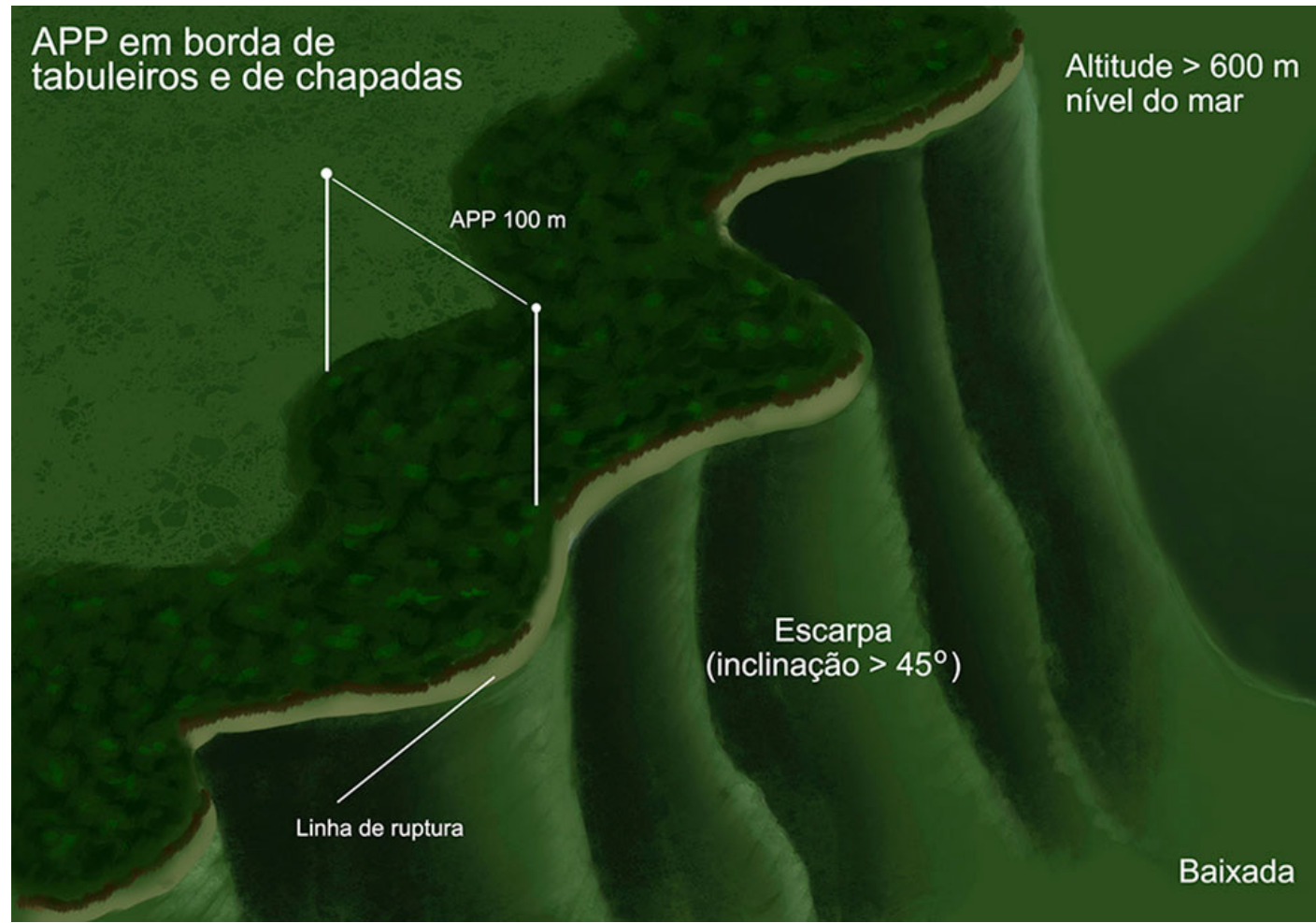

Fonte: http://www.ciflorestas.com.br/cartilha/. Acesso em: 15/Nov/2016. 


\section{Dando passos mais firmes com a lei norteadora: a Política Nacional do Meio Ambiente}

Mesmo com dois códigos florestais (1934 e 1965), até o início dos anos 1980 podese dizer que não havia uma legislação efetiva e ampla de proteção do meio ambiente no Brasil. O que havia, até então, eram regulamentações com ordenamentos relativos às águas e às florestas, com o objetivo aparentemente maior de proteção e sustentabilidade de determinados quadros econômicos do que a específica e prioritária proteção ambiental.

Assim, em 1981, sob a égide de uma maior importância do desenvolvimento sustentável no mundo, que chega no Brasil sob a forma de exigência (cada vez maior e muito atual) de organismos estrangeiros para empréstimos e financiamentos, tem-se a promulgação da Lei Federal n 6.938/1981, que dispõe sobre a Política Nacional do Meio Ambiente (PNMA) que, conforme seu art. $2^{\circ}$, tem por objetivo a preservação, melhoria e recuperação da qualidade ambiental propícia à vida, visando assegurar, no País, condições ao desenvolvimento socioeconômico, aos interesses da segurança nacional e à proteção da dignidade da vida humana (BRASIL, 1981).

Toda essa lei, vigente e muito importante, deve ser apreciada com atenção e ser tida como um verdadeiro item de cabeceira para quem trabalha com legislação ambiental. Aqui, vamos destacar o art. $9^{\circ}$ que traz os instrumentos da Política Nacional do Meio Ambiente e, entre parênteses, parte de seus desdobramentos que identificamos como presentes em outros diplomas legais:

I - o estabelecimento de padrões de qualidade ambiental (instrumento que derivou em inúmeras normas técnicas e resoluções nas três esferas do Poder Público e que determinam padrões para qualidade do ar, das águas, do solo, dentre outras);

II - o zoneamento ambiental (instrumento que se notabiliza como um produto cartográfico fundamental para determinação de formas / zonas de uso e ocupação de qualquer área, elaborado a partir de diversos elementos da legislação ambiental cabíveis; essencialmente aplicável e que possibilita o desdobramento de etapas importantes do licenciamento ambiental - Figura 4);

III - a avaliação de impactos ambientais (etapa fundamental de qualquer processo de licenciamento ambiental);

IV - o licenciamento e a revisão de atividades efetiva ou potencialmente poluidoras (condição básica para implantação de empreendimentos que façam uso de recursos naturais); 
$\mathrm{V}$ - os incentivos à produção e instalação de equipamentos e a criação ou absorção de tecnologia, voltados para a melhoria da qualidade ambiental (instrumento derivado diretamente do princípio econômico do desenvolvimento sustentável, conforme visto anteriormente);

VI - a criação de espaços territoriais especialmente protegidos pelo Poder Público federal, estadual e municipal, tais como áreas de proteção ambiental, de relevante interesse ecológico e reservas extrativistas (instrumento que derivou na criação das Unidades de Conservação, elemento legal fundamental no contexto da legislação ambiental brasileira);

VII - o sistema nacional de informações sobre o meio ambiente (presente nos processos de licenciamento);

VIII - o Cadastro Técnico Federal de Atividades e Instrumentos de Defesa Ambiental (outro instrumento presente nos processos de licenciamento);

IX - as penalidades disciplinares ou compensatórias ao não cumprimento das medidas necessárias à preservação ou correção da degradação ambiental (instrumento que originou a lei de crimes ambientais, promulgada no final dos anos 1990); 
Figura 4: Exemplo de Mapa de zoneamento ambiental.

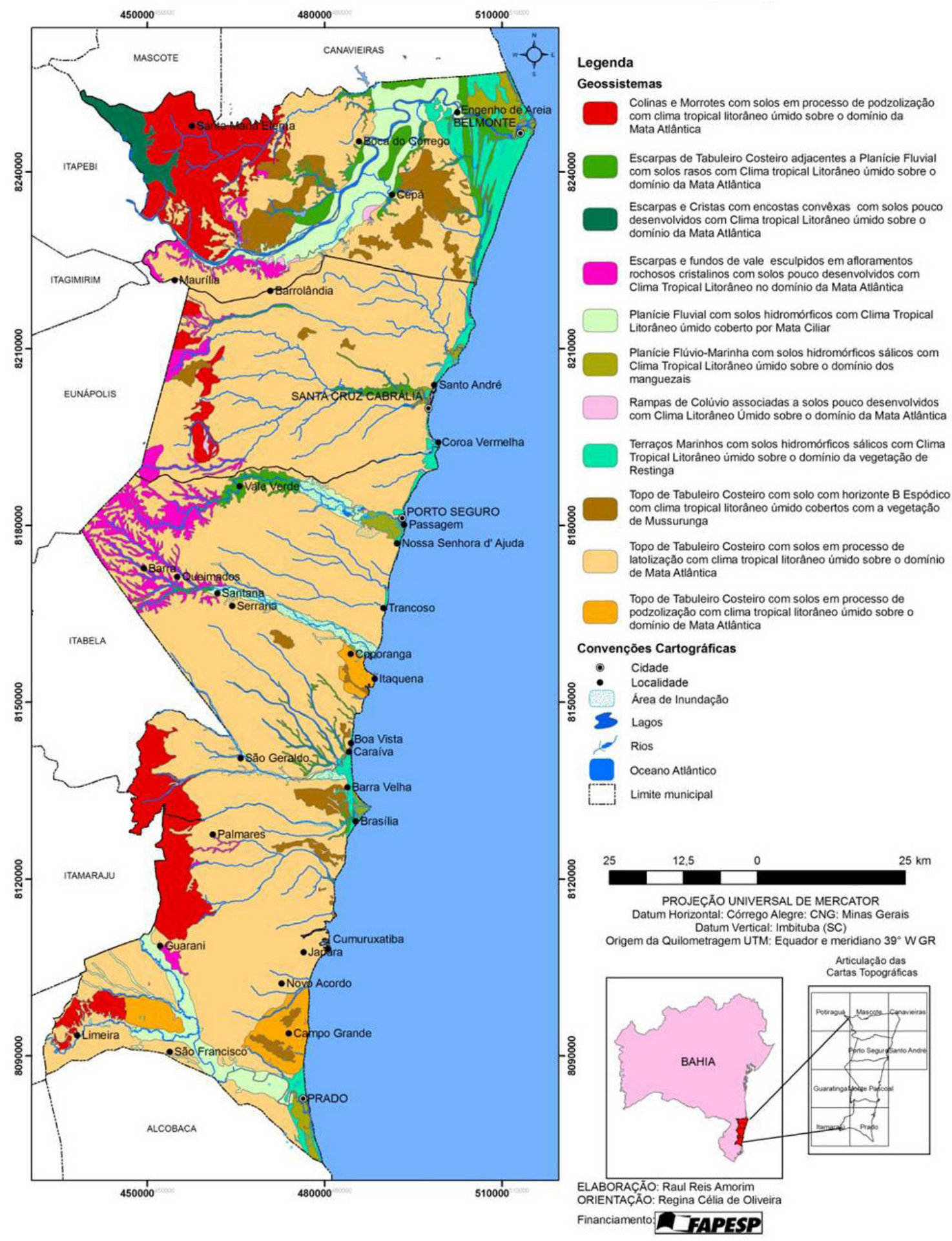

Fonte: Amorim e Oliveira, 2013. 
Os inúmeros avanços feitos direta e indiretamente pela Política Nacional do Meio Ambiente, a maior parte deles, conforme sucintamente mencionado, se deu anos depois de seu sancionamento e, dentre eles, vale destacar a incursão concreta e clara das questões ambientais na lei magna brasileira, a Constituição Federal de 1988.

\section{No epicentro do labirinto: eis o nosso Minotauro}

Chegamos ao principal diploma legal do Brasil, a Constituição Federal de 1988 (BRASIL, 1988), a qual, a partir de sua promulgação, configurou-se como o ponto central para todas as discussões legais em suas mais diversas áreas, um elemento norteador para os principais valores legais do país, o que não foi diferente em relação à legislação ambiental e, portanto, é o epicentro do nosso labirinto.

No art. 23 da Constituição Federal Brasileira de 1988, que trata das competências comuns dos entes federativos, há a expressa descentralização da proteção do meio ambiente, o que pode ser verificado nos itens presentes nos parágrafos III (paisagens naturais notáveis e sítios arqueológicos), VI (proteger o meio ambiente e combater a poluição em qualquer de suas formas) e VII (florestas, a fauna e a flora). No art. 24 tem-se a consolidação de que, a partir de então, União, Estados, Municípios e Distrito Federal passaram a ter ampla competência para legislarem em matéria ambiental.

Assim, aos estados-membros foi dada a competência de legislar plenamente para atender às suas particularidades quando a União não editar norma geral. Após a Constituição Federal de 1988 verifica-se que os municípios adquiriram uma especial importância, sendo entes autônomos. Dessa forma, podem e devem agir em prol da proteção do meio ambiente, sendo a atuação de tais entes, fundamental para a proteção do patrimônio ambiental numa escala local.

Vale frisar que a legislação concorrente dos entes das três esferas (art. 24 da CF1988) deve obedecer um princípio básico: o de que os entes estaduais não podem adotar leis menos restritas que a esfera federal e, por conseguinte, os entes municipais do Poder Público não podem ser menos restritos que os Estados.

Em seu artigo 225 a Constituição Federal fixou os princípios gerais em relação ao Meio Ambiente e estabeleceu, no $3^{\circ}$ parágrafo, inspirado no instrumento IX da Política Nacional do Meio Ambiente (BRASIL, 1981), que nas condutas e nas atividades lesivas ao Meio Ambiente, os infratores, sejam pessoas físicas ou jurídicas, ficariam sujeitos às sanções penais e administrativas e, além disso, independentemente da obrigação de reparar o dano causado (GOMES, 2008). 
Esse parágrafo, em definitivo, colocou na pauta a necessidade de se fazer uma lei mais severa no tocante à proteção ambiental. Assim, uma década depois, em 1998, foi promulgada a lei federal no 9.605, de 12 de fevereiro de 1998 (BRASIL, 1998), a lei de Crimes Ambientais, que dispõe sobre as sanções penais e administrativas derivadas de condutas e atividades lesivas ao meio ambiente.

Essa lei trouxe penas mais duras para quem desobedecesse a legislação ambiental. Em seu art. $8^{\circ}$, que trata das penas restritivas de direito, há a relação delas, a saber: I - prestação de serviços à comunidade; II - interdição temporária de direitos; III - suspensão parcial ou total de atividades; IV - prestação pecuniária; e V - recolhimento domiciliar. Por sua vez, o art. 21 fala das penas aplicáveis isolada, cumulativa ou alternativamente às pessoas jurídicas, de acordo com o disposto no art. $3^{\circ}$, que são: I - multa; II - restritivas de direitos; e III - prestação de serviços à comunidade (BRASIL, 1998).

Assim, entendemos que a Lei de Crimes Ambientais representa o minotauro da história de Teseu, ao passo que, pelo menos no teor de suas letras, ela se apresenta de forma implacável para todos aqueles que cometerem crimes contra o meio ambiente (capítulo V), seja contra a fauna (seção I), contra a flora (seção II), que poluam (seção III), que destruam, inutilizem ou deteriorem o patrimônio urbano ou cultural (seção IV), dentre outros itens.

Aliás, o art. $2^{\circ}$ é claro quando diz que:

\footnotetext{
Quem, de qualquer forma, concorre para a prática dos crimes previstos nesta Lei, incide nas penas a estes cominadas, na medida da sua culpabilidade, bem como o diretor, o administrador, o membro de conselho e de órgão técnico, o auditor, o gerente, o preposto ou mandatário de pessoa jurídica, que, sabendo da conduta criminosa de outrem, deixar de impedir a sua prática, quando podia agir para evitá-la (BRASIL, 1998, art. $2^{\circ}$ ).
}

Sabemos que, de maneira geral, o papel dos vilões nas histórias tem um caráter básico: o de estimular os heróis à enfrentar seus limites, seus medos, os fazendo evoluir e tomar atitudes e realizar feitos os quais, eles mesmos se julgavam incapazes de realizar. Aqui, nosso minotauro, mais do que ser temido, acima de tudo, ele precisa ser respeitado, sendo encarado com seriedade e estudado de forma pormenorizada em cada um das suas dezenas de artigos, sob a (literal) pena de entrar nesse labirinto e não conseguir sair.

\section{O Novelo se desenrola ainda mais: a Lei do SNUC}

Em 18 de julho de 2000 foi promulgada a lei federal no 9.985 que institui o Sistema Nacional de Unidades de Conservação da Natureza, o SNUC, estabelecendo critérios e normas para a criação, implantação e gestão das unidades de conservação (UCs), sendo estas entendidas 
como um: "espaço territorial e seus recursos ambientais, incluindo as águas jurisdicionais, com características naturais relevantes, legalmente instituído pelo Poder Público, com objetivos de conservação e limites definidos, sob regime especial de administração, ao qual se aplicam garantias adequadas de proteção" (BRASIL, 2000, art. 2º parágrafo I).

Junto com as APPs, as UCs representam os principais referenciais legais na defesa do meio ambiente no Brasil e têm no SNUC sua principal forma de organização, o qual, por sua vez, é gerido pelos seguintes órgãos, com as respectivas atribuições:

I - Órgão consultivo e deliberativo: o Conselho Nacional do Meio Ambiente - Conama, com as atribuições de acompanhar a implementação do Sistema;

II - Órgão central: o Ministério do Meio Ambiente, com a finalidade de coordenar o Sistema; e

III - órgãos executores: o Instituto Chico Mendes e o Ibama, em caráter supletivo, os órgãos estaduais e municipais, com a função de implementar o SNUC, subsidiar as propostas de criação e administrar as unidades de conservação federais, estaduais e municipais, nas respectivas esferas de atuação (BRASIL, 2000, art. $6^{\circ}$, friso nosso).

De maneira geral, as UCs integrantes do SNUC dividem-se em dois grupos, com características específicas, conforme pode ser visto no Quadro 1:

Quadro 1 - Categorias de Unidades de Conservação

\section{SISTEMA NACIONAL DE UNIDADES DE CONSERVAÇÃO DA NATUREZA (SNUC)}

\begin{tabular}{|c|c|c|}
\hline Grupo & Característica & Categorias \\
\hline \multirow{5}{*}{$\begin{array}{l}\text { Unidades } \\
\text { de Proteção } \\
\text { Integral }\end{array}$} & \multirow{5}{*}{$\begin{array}{c}\text { Visam preservar a } \\
\text { natureza, admitindo } \\
\text { apenas o uso indireto dos } \\
\text { seus recursos naturais, } \\
\text { com exceção dos casos } \\
\text { previstos em lei. }\end{array}$} & (I) Estação Ecológica \\
\hline & & (II) Reserva Biológica \\
\hline & & (III) Parque Nacional (PARNA) \\
\hline & & (IV) Monumento Natural \\
\hline & & (V) Refúgio de Vida Silvestre \\
\hline
\end{tabular}

\begin{tabular}{|c|c|c|}
\hline \multirow{7}{*}{$\begin{array}{c}\text { Unidades } \\
\text { de Uso } \\
\text { Sustentável }\end{array}$} & \multirow{7}{*}{$\begin{array}{c}\text { Visam compatibilizar a } \\
\text { conservação da natureza } \\
\text { com o uso sustentável de } \\
\text { parcela dos seus recursos } \\
\text { naturais. }\end{array}$} & (I) Área de Proteção Ambiental (APA) \\
\hline & & (II) Área de Relevante Interesse Ecológico (ARIE) \\
\hline & & (III) Floresta Nacional (FLONA) \\
\hline & & (IV) Reserva Extrativista (RESEX) \\
\hline & & (V) Reserva de Fauna (REFAU) \\
\hline & & (VI) Reserva de Desenvolvimento Sustentável (RDS) \\
\hline & & (VII) Reserva Particular do Patrimônio Natural (RPPN) \\
\hline
\end{tabular}

Fonte: BRASIL, 2000, in: MOURA-FÉ, 2015. 
Vale frisar que por trás do sucinto quadro há uma grande diversidade de características peculiares, obviamente correlata à diversidade natural do Brasil. Cada UC tem sua importância e que, para tenha seu potencial de defesa do meio ambiente efetivado, precisa ser conhecida ao máximo. Para tal, um documento é imprescindível: o plano de manejo, o qual precisa ser elaborado e posto em prática de forma efetiva.

O plano de manejo é um "documento técnico mediante o qual, com fundamento nos objetivos gerais de uma unidade de conservação, se estabelece o seu zoneamento e as normas que devem presidir o uso da área e o manejo dos recursos naturais, inclusive a implantação das estruturas físicas necessárias à gestão da unidade" (BRASIL, 2000, art. $2^{\circ}$, parágrafo XVII).

\section{Quase saindo do labirinto: Resoluções Conama}

Estamos quase no final da nossa viagem e, antes disso, precisamos conhecer as principais Resoluções do Conselho Nacional do Meio Ambiente - Conama, órgão consultivo e deliberativo do Sistema Nacional do Meio Ambiente - Sisnama, que foi instituído pela Lei $n^{\circ}$ 6.938/1981 (BRASIL, 1981). O Conselho é um colegiado com órgãos federais, estaduais e municipais, setor empresarial e sociedade civil, que tem as seguintes competências: estabelecer, mediante proposta do Ibama, normas e critérios para o licenciamento de atividades efetiva ou potencialmente poluidoras, a ser concedido pelos Estados e supervisionado pelo Ibama (MMA, 2012a).

As resoluções Conama são várias e o desafio é identificar quais são as mais interessantes e pertinentes para os trabalhos que estamos desenvolvendo. Obviamente, esse entendimento só vai se dar de forma satisfatória para cada pessoa (e seus interesses) com o passar do tempo e com o desenvolvimento das nossas experiências.

Abaixo, apresentamos uma breve lista daquelas que nossa experiência aponta como imprescindíveis para o conhecimento básico das resoluções do Conama:

- Conama no 001/1986, dispõe sobre critérios básicos e diretrizes gerais para a avaliação de impacto ambiental;

- Conama n 237/1997, dispõe sobre a revisão e complementação dos procedimentos e critérios utilizados para o licenciamento ambiental;

- Conama no 369/2006, dispõe sobre os casos excepcionais, de utilidade pública, interesse social ou baixo impacto ambiental, que possibilitam a intervenção ou supressão de vegetação em APP. 
Detalhando um pouco a Resolução Conama no 001, de 23 de janeiro de 1986, de antemão, ela perfaz uma clássica conceituação em seu art. $1^{\circ}$ do que considera como impacto ambiental:

qualquer alteração das propriedades físicas, químicas e biológicas do meio ambiente, causada por qualquer forma de matéria ou energia resultante das atividades humanas que, direta ou indiretamente, afetam:

I - a saúde, a segurança e o bem-estar da população;

II - as atividades sociais e econômicas;

III - a biota;

IV - as condições estéticas e sanitárias do meio ambiente;

$\mathrm{V}$ - a qualidade dos recursos ambientais (CONAMA, 1986, art. $1^{\circ}$ ).

É exatamente esta resolução que vai estabelecer em seu art. $2^{\circ}$ a necessidade de se elaborar um estudo ambiental, ao passo que o estudo de impacto ambiental (EIA) e respectivo relatório de impacto ambiental (RIMA) são os mais complexos, a serem submetidos à aprovação do órgão ambiental competente para fins de licenciamento de atividades modificadoras do meio ambiente. Apenas por este artigo esta resolução já tem sua importância exemplificada.

Esta resolução diz ainda que o estudo de impacto ambiental, além de atender à legislação, em especial os princípios e objetivos expressos na lei da PNMA (olha ela aqui de novo), obedecerá às seguintes diretrizes gerais:

I - Contemplar todas as alternativas tecnológicas e de localização do projeto, confrontandoas com a hipótese de não execução do projeto;

II - Identificar e avaliar sistematicamente os impactos ambientais gerados nas fases de implantação e operação da atividade;

III - Definir os limites da área geográfica a ser direta ou indiretamente afetada pelos impactos, denominada área de influência do projeto, considerando, em todos os casos, a bacia hidrográfica na qual se localiza;

IV - Considerar os planos e programas governamentais, propostos e em implantação na área de influência do projeto, e sua compatibilidade (CONAMA, 1986, Art. 5º, friso nosso).

Do ponto de vista técnico, o estudo de impacto ambiental desenvolverá, conforme essa resolução, no mínimo, as seguintes atividades técnicas:

I - Diagnóstico ambiental da área de influência do projeto completa descrição e análise dos recursos ambientais e suas interações, tal como existem, de modo a caracterizar a situação ambiental da área, antes da implantação do projeto, considerando: 
a) o meio físico - o subsolo, as águas, o ar e o clima, destacando os recursos minerais, a topografia, os tipos e aptidões do solo, os corpos d'água, o regime hidrológico, as correntes marinhas, as correntes atmosféricas;

b) o meio biológico e os ecossistemas naturais - a fauna e a flora, destacando as espécies indicadoras da qualidade ambiental, de valor científico e econômico, raras e ameaçadas de extinção e as áreas de preservação permanente;

c) o meio sócio-econômico - o uso e ocupação do solo, os usos da água e a sócioeconomia, destacando os sítios e monumentos arqueológicos, históricos e culturais da comunidade, as relações de dependência entre a sociedade local, os recursos ambientais e a potencial utilização futura desses recursos.

II - Análise dos impactos ambientais do projeto e de suas alternativas, através de identificação, previsão da magnitude e interpretação da importância dos prováveis impactos relevantes, discriminando: os impactos positivos e negativos (benéficos e adversos), diretos e indiretos, imediatos e a médio e longo prazos, temporários e permanentes; seu grau de reversibilidade; suas propriedades cumulativas e sinérgicas; a distribuição dos ônus e benefícios sociais.

III - Definição das medidas mitigadoras dos impactos negativos, entre elas os equipamentos de controle e sistemas de tratamento de despejos, avaliando a eficiência de cada uma delas.

IV - Elaboração do programa de acompanhamento e monitoramento dos impactos positivos e negativos, indicando os fatores e parâmetros a serem considerados (CONAMA, 1986, Art. $6^{\circ}$, friso nosso).

Ou seja, para começar a falar de estudos de impacto ambiental, é imprescindível conhecer e, mais que isso, atender aos dispositivos básicos contidos na Resolução Conama $n^{\circ} 01 / 1986$, ainda vigente e que se configura como um verdadeiro marco referencial no labirinto da legislação ambiental.

Por sua vez, a Resolução Conama n 237/1997 traz importantes elementos imprescindíveis na legislação ambiental brasileira, tal como o entendimento geral do processo de:

Licenciamento ambiental, procedimento administrativo pelo qual o órgão ambiental competente licencia a localização, instalação, ampliação e a operação de empreendimentos e atividades utilizadoras de recursos ambientais, consideradas efetiva ou potencialmente poluidoras ou daquelas que, sob qualquer forma, possam causar degradação ambiental, considerando as disposições legais e regulamentares e as normas técnicas aplicáveis ao caso (CONAMA, 1997, art. $1^{\circ}$, parágrafo I).

E também do que vem a ser a:

Licença Ambiental: ato administrativo pelo qual o órgão ambiental competente, estabelece as condições, restrições e medidas de controle ambiental que deverão ser obedecidas pelo empreendedor, pessoa física ou jurídica, para localizar, instalar, ampliar e operar empreendimentos ou atividades utilizadoras dos recursos ambientais consideradas efetiva ou potencialmente poluidoras ou aquelas que, sob qualquer forma, possam causar degradação ambiental (CONAMA, 1997, art. $1^{\circ}$, parágrafo II). 
Que por sua vez é compartimentada desde então nas seguintes etapas:

I - Licença Prévia (LP) - concedida na fase preliminar do planejamento do empreendimento ou atividade aprovando sua localização e concepção, atestando a viabilidade ambiental e estabelecendo os requisitos básicos e condicionantes a serem atendidos nas próximas fases de sua implementação;

II - Licença de Instalação (LI) - autoriza a instalação do empreendimento ou atividade de acordo com as especificações constantes dos planos, programas e projetos aprovados, incluindo as medidas de controle ambiental e demais condicionantes, da qual constituem motivo determinante;

III - Licença de Operação (LO) - autoriza a operação da atividade ou empreendimento, após a verificação do efetivo cumprimento do que consta das licenças anteriores, com as medidas de controle ambiental e condicionantes determinados para a operação.

Parágrafo único. As licenças ambientais poderão ser expedidas isolada ou sucessivamente, de acordo com a natureza, características e fase do empreendimento ou atividade (CONAMA, 1997, art. $8^{\circ}$.

Complementando a Resolução Conama nº 01/1986, a Resolução Conama n 237/1997 traz uma conceituação interessante e mais abrangente do que vem a ser os estudos ambientais:

São todos e quaisquer estudos relativos aos aspectos ambientais relacionados à localização, instalação, operação e ampliação de uma atividade ou empreendimento, apresentado como subsídio para a análise da licença requerida, tais como: relatório ambiental, plano e projeto de controle ambiental, relatório ambiental preliminar, diagnóstico ambiental, plano de manejo, plano de recuperação de área degradada e análise preliminar de risco (CONAMA, 1997, art. 1º, parágrafo III).

Dentre os estudos ambientais exigíveis e normalmente solicitados, destacam-se:

- EIA-RIMA;

- Estudo de Viabilidade Ambiental - EVA: elaborado nos casos mais simples, de não exigência do EIA / RIMA;

- Relatório Ambiental Simplificado - RAS: utilizado no licenciamento de empreendimentos de matriz energética renovável;

- Plano de Controle Ambiental - PCA: define e detalha, através de projetos executivos, as medidas de controle ambiental que serão implementadas concomitantemente com a implantação do empreendimento;

- Relatório de Controle Ambiental - RCA: documento a ser apresentado sistematicamente para as atividades de mineração, conforme previsto no PCA; 
- Plano de Recuperação de Área Degradada - PRAD: visa a recuperação de áreas degradadas, ou seja, propicia a reintegração das mesmas ao ecossistema;

- Plano de Manejo. Voltado para as Unidades de Conservação, conforme visto anteriormente.

É importante informar que todo estudo ambiental deve atender às determinações contidas no Termo de Referência (TR), documento elaborado pelo corpo técnico do órgão ambiental e que orientam a elaboração de estudos ambientais. De forma indicativa um TR deve ser elaborado de acordo com o seguinte roteiro, o qual precisa ser integralmente contemplado para que haja seguimento no processo de licenciamento ambiental:

Objetivo; Metodologia do trabalho; Área de abrangência do estudo; Descrição do empreendimento ou atividade; Alternativas locacionais e tecnológicas do empreendimento; Caracterização ambiental da área de influencia do projeto; Legislação aplicável; Concepção do estudo e metodologia de análise dos impactos; Formas de mitigação e compensação dos impactos negativos; Restrições e recomendações institucionais; Medidas de monitoramento e controle ambiental; Conclusões; Bibliografia; Equipe técnica de elaboração dos estudos com Anotação de Responsabilidade Técnica - ART; Forma de apresentação do estudo ambiental; Documentação fotográfica e Anexos.

\section{Antes de sair: cuidado com resolução Conama 369/2006}

A saída do labirinto está logo ali, já desfiamos o nosso novelo em diversas conceituações e diplomas legais referenciais para a legislação ambiental, incluindo o nosso minotauro, a lei de crimes ambientais. Contudo, antes de sair é importante conhecer as linhas gerais de uma resolução Conama que modifica de forma significativa toda a argumentação apresentada até aqui, toda a construção histórica da legislação ambiental brasileira e que, sem exageros, coloca sob risco os avanços alcançados, é a Resolução CONAMA nº 369/2006.

Em seu art. $1^{\circ}$ esta resolução define os casos excepcionais em que o órgão ambiental competente pode autorizar a intervenção ou supressão de vegetação em APP para a implantação de obras, planos, atividades ou projetos de utilidade pública ou interesse social, ou para a realização de ações consideradas eventuais e de baixo impacto ambiental (CONAMA, 2006), solapando na base o princípio de intocabilidade legal que tinham as APPs.

Como isso se dá? O órgão ambiental competente somente poderá autorizar a intervenção ou supressão de vegetação em APP, devidamente caracterizada e motivada mediante procedimento administrativo autônomo e prévio, e atendidos os requisitos previstos na 
própria resolução e noutras normas federais, estaduais e municipais aplicáveis, bem como no Plano Diretor, Zoneamento Ecológico-Econômico e Plano de Manejo das Unidades de Conservação, se existentes (CONAMA, 2006, art. $2^{\circ}$ ).

No art. $3^{\circ}$ da resolução está o cerne técnico da questão, ao passo que ela diz que a intervenção ou supressão de vegetação em APP somente poderá ser autorizada quando o requerente, entre outras exigências, comprovar:
I - a inexistência de alternativa técnica e locacional as obras, planos, atividades ou projetos propostos;
II - atendimento as condições e padrões aplicáveis aos corpos de água;
III - averbação da Área de Reserva Legal; e
IV - a inexistência de risco de agravamento de processos como enchentes, erosão ou movimentos acidentais de massa rochosa (CONAMA, 2006, art. $3^{\circ}$, friso nosso).

Apesar de parecer longo e aparentemente complicado, os requisitos apresentados nos artigos supracitados se resumem a um relatório técnico de 4 itens básicos a ser apresentado pelo empreendedor num processo administrativo autônomo e prévio. Nesse mesmo contexto, a determinação municipal do poder público caracterizando o empreendimento proposto como sendo de utilidade pública, interesse social ou de baixo impacto ambiental também tem peso decisório para a permissão da intervenção em APP, o que pode ser influenciado por questões políticas, as quais não necessariamente tem compromisso com as reais demandas socioambientais.

Antes de nos despedirmos do labirinto de Dédalo, vale mencionar três diplomas legais que versam sobre questões ambientais fundamentais para o meio ambiente, são políticas nacionais que também precisam estar na lista de leituras de pesquisadores e técnicos que trabalham com legislação ambiental, são elas:

- Lei federal no 9.433, de 8 de janeiro de 1997. Institui a Política Nacional de Recursos Hídricos, cria o Sistema Nacional de Gerenciamento de Recursos Hídricos, regulamenta o inciso XIX do art. 21 da Constituição Federal, e altera 0 art. $1^{\circ}$ da Lei $n^{\circ} 8.001$, de 13 de março de 1990, que modificou a Lei $n^{\circ} 7.990$, de 28 de dezembro de 1989.

- Lei federal $\mathrm{n}^{\mathrm{0}}$ 12.305, de 2 de agosto de 2010. Institui a Política Nacional de Resíduos Sólidos; altera a Lei no 9.605, de 12 de fevereiro de 1998; e dá outras providências.

- Lei federal n 9.795, de 27 de abril de 1999. Dispõe sobre a educação ambiental, institui a Política Nacional de Educação Ambiental e dá outras providências. 


\section{CONSIDERACÕES FINAIS: RETORNAR É PRECISO}

Conforme relatado, nosso novelo de Teseu da legislação ambiental não tem a pretensão de ser uma espécie de manual completo de consulta sobre essa importante e complexa temática, cada vez mais presente no nosso cotidiano. Nosso objetivo aqui foi de fazer uma apresentação crítica e analítica dos principais diplomas legais, seus preceitos conceituais, sua construção histórica e uma interrelação básica dos temas que, por fim, dialogam entre si nas mais diversas instâncias do poder público e da sociedade.

A natureza é dinâmica, a sociedade e seus interesses também, e a legislação ambiental está em constante necessidade de evolução, para tentar acompanhar essa dinâmica e, portanto, sempre mudando, em vias de mudar ou sob pressão para mudar. Sendo assim, é peremptória a necessidade de retornos cada vez mais regulares a esse labirinto a partir das necessidades particulares e/ou institucionais de trabalho e pesquisa, com a finalidade básica de se aprofundar em cada uma das diversas temáticas embutidas no contexto da legislação ambiental.

Por outro lado, nesse contexto de dinamicidade é importante estar atento à criação de normas que possam retroagir na proteção do meio ambiente, criando situações de favorecimento a determinados atores sociais que, historicamente, não são defensores do tão desejado equilíbrio socioambiental.

Nesse contexto dinâmico, complexo e muito interessante, acreditamos que com esse artigo você possa fazer essa imersão, seguro em fazer novas descobertas e em sempre encontrar o caminho de volta, sem medo de ter o minotauro à espreita, confiante de que é esse o processo para realizar sua contribuição para as melhorias das condições do nosso meio ambiente.

\section{AGRADECIMENTOS}

O processo de aprendizado não é possível sem a contribuição e orientação daqueles que detém experiência, capacidade e disponibilidade de repassar conhecimento. Sendo assim, queremos agradecer e reconhecer o trabalho de pessoas que nos ajudaram à, indiretamente, elaborar este trabalho e, diretamente, nos conduzir de forma segura através do labirinto da legislação ambiental. 
Agradecemos aos geólogos Tadeu Dote Sá, Lucinaura Diógenes, Celso Favalli e Orlando Silva, à bióloga Valéria Trece, ao advogado Daniel Lima (queridos companheiro de trabalho na Geoconsult); e ao arquiteto João Bosco Campos de Moura (in memoriam).

À Companhia de Gestão de Recursos Hídricos (COGERH), em especial ao amigo Raimundo Lauro, pelas sugestões e conselhos para uma melhoria na vida profissional e dar ânimo para continuar as leituras para desenvoltura deste artigo.

\section{REFERÊNCIAS}

1. AMORIM, R. A.; OLIVEIRA, R. C. Zoneamento Ambiental Como Subsídio ao Planejamento no Uso e Ocupação das Terras da Costa do Descobrimento. Mercator (Fortaleza-CE), v. 12, n. 29, p. 211-231, 2013.

2. BRASIL. Casa Civil. Código Florestal de 1934. Jornal do Senado Federal. Disponível em: $<$ http://www.senado.gov.br/NOTICIAS/JORNAL/EMDISCUSSAO/codigo-florestal/senadooferece-um-projeto-equilibrado-para-o-novo-codigo-florestal-brasileiro/codigo-florestalde-1934.aspx>, acesso em: 28 jul. 2012a.

3. Código Florestal de 1965. Jornal do Senado Federal. Disponível em: <http://www. senado.gov.br/NOTICIAS/JORNAL/EMDISCUSSAO/codigo-florestal/senado-oferece-umprojeto-equilibrado-para-o-novo-codigo-florestal-brasileiro/codigo-florestal-de-1965.aspx>, acesso em: 28 de jul. 2012 b.

4. . Constituição da Republica Federativa do Brasil. Brasília: Editora Senado, 1988.

5. Decreto-lei no 4.771 , de 15 de setembro de 1965. Institui o Novo Código Florestal Brasileiro e dá outras providências. Diário Oficial (da) República Federativa do Brasil. Poder Executivo. Brasília, DF, 1965.

6. . Lei Federalo 9.605, de 12 de fevereiro de 1998. Dispõe sobre as sanções penais e administrativas derivadas de condutas e atividades lesivas ao meio ambiente, e dá outras providências. Poder Executivo. Brasília, DF, 1998.

7.

. Lei Federalo 9.985, de 18 de julho de 2000. Regulamenta o art. 225, $\$ 1^{\circ}$, incisos I, II, III e VII da Constituição Federal, institui o Sistema Nacional de Unidades de Conservação da Natureza e dá outras providências. Diário Oficial (da) República Federativa do Brasil. Poder Executivo. Brasília, DF, 2000.

8. . Lei Federal no 6.938, de 31 de agosto de 1981. Dispõe sobre a Política Nacional do Meio Ambiente. Poder Executivo. Brasília, DF, 1981.

9. . Lei Federal no 12.727, de 17 de outubro de 2012. Dispõe sobre alterações no Código Florestal. Poder Executivo. Brasília, DF, 2012c.

10. BRASIL. MMA - Ministério do Meio Ambiente. Agenda 21 brasileira - ações prioritárias. v. 2. Brasília, DF: MMA/PNUD, 2002. 133 p. 
11. Programa Nacional de Capacitação de gestores ambientais: licenciamento ambiental Ministério do Meio Ambiente. - Brasília: MMA, 2009. 90 p.

12. BULFINCH, T. O Livro de Ouro da mitologia: histórias de deuses e heróis. 34 ed. 5 a reimpressão. Trad. David Jardim. Rio de Janeiro: Ediouro, 2006.

13. CONAMA. Conselho Nacional do Meio Ambiente. Resolução CONAMA no $\mathbf{1}$, de 23 de janeiro de 1986. Brasília: MMA/CONAMA, 1986.

14. . Resolução CONAMA n² 237/1997. Brasília: MMA/CONAMA, 1997.

15. Resolução CONAMA n 369/2006. Brasília: MMA/CONAMA, 2006.

16. GOMES, A. Legislação Ambiental e Direito: um Olhar sobre o Artigo 225 da Constituição Federativa do Brasil. Revista Científica Eletrônica de Administração, n. 14, p.01-11, 2008.

17. HOBBES, T. Leviatã. Ou matéria, forma e poder de um estado eclesiástico e civil. 1651. Trad. Rosina D’Angina. São Paulo: Martin Claret, 2014.

18. MARCHIORO, E.; FERNANDES, N. F.; MACEDO, J. R.; BHERING, S. B. e GONÇALVEZ, A. O. Aplicação do Código Florestal Brasileiro como Subsídio para o Planejamento Ambiental: um Estudo de Caso na Região Noroeste do Estado do Rio de Janeiro. Sociedade e Natureza. Uberlândia, n. 22, v. 1, p. 11-21, 2010.

19. MMA. Ministério do Meio Ambiente / CONAMA. Conselho Nacional do Meio Ambiente. Resoluções do CONAMA: resoluções vigentes publicadas entre setembro de 1984 e janeiro de 2012. Brasília: MMA, 2012.

20. MOURA-FÉ, M. M. Evolução Geomorfológica da Ibiapaba setentrional, Ceará: Gênese, Modelagem e Conservação. 307 f. Tese (Doutorado em Geografia). Centro de Ciências, Universidade Federal do Ceará, Fortaleza, CE, 2015.

21. MOURA-FÉ, M. M.; ALBUQUERQUE, A. G. B. M. e FREITAS, E. M. N. A proteção do ecossistema manguezal pela legislação dos estados do Nordeste brasileiro. Estudos Geográficos - UNESP (Rio Claro-SP), v. 12, n. 2, p. 30-44, 2014.

22. MOURA-FÉ, M. M.; ALBUQUERQUE, A. G. B. M.; FREITAS, E. M. N. e BARBOSA, W. R. A proteção dos ecossistemas de manguezal pela legislação ambiental brasileira. GEOgraphia UFF (Rio de Janeiro-RJ), v. 17, n. 33, p. 120-147, 2015.

23. PINHEIRO, M. V. A.; MOURA-FÉ, M. M.; FREITAS, E. M. N.; COSTA, A. T.; AGUIAR, A. C. S.; SOMBRA, E. T. P. Dunas móveis: Áreas de Preservação Permanente? Revista Sociedade \& Natureza - UFU (Uberlândia-MG), v. 25, n. 3, p. 595-607, 2013 a.

24. PINHEIRO, M. V. A.; MOURA-FÉ, M. M. e FREITAS, E. M. N. Os Ecossistemas dunares e a legislação ambiental brasileira. Revista GeoUERJ (Rio de Janeiro-RJ), v. 24, n. 2, p. 1-26, 2013 b.

25. SIRVINSKAS, L. P. Manual de Direito Ambiental. 13 ed. São Paulo: Saraiva, 2015.

ARTIGO RECEBIDO EM DEZEMBRO DE 2016

ARTIGO APROVADO EM ABRIL DE 2017 